\title{
Padrão de Nidificação de Monobia angulosa Saussure (Vespidae) Durante Estação Seca Prolongada na Região da Chapada Diamantina, Bahia, com Notas Sobre Nidificação em Ninho Abandonado de Xylocopa cearensis Ducke (Apidae)
}

\author{
Thiago Mahlmann ${ }^{\bowtie}$, Reinanda Lima² ${ }^{2}$ Taniele Santana ${ }^{3}$, Jeferson Gabriel da Encarnação Coutinho ${ }^{3}$ \\ Favízia Freitas de Oliveira ${ }^{3}$
}

1. Instituto Nacional de Pesquisas da Amazônia, e-mail: thiago.mahlmann@inpa.gov.br (Autor para correspondência ${ }^{\varpi}$ ). 2. Faculdade de Filosofia, Ciências e Letras de Ribeirão Preto, e-mail: reinandalima@gmail.com. 3. Universidade Federal da Bahia, e-mail: tanyele@hotmail.com, jeferson.gabriel@gmail.com, favosgyrl@gmail.com.

\section{EntomoBrasilis 8 (1): 12-16 (2015)}

Resumo. Alguns estudos evidenciam que condições climáticas são fatores relevantes no padrão de nidificação de várias espécies de vespas solitárias. O presente estudo avaliou o padrão de nidificação da vespa Monobia angulosa Saussure (Vespidae: Eumeninae) no pólo agrícola Mucugê-Ibicoara, Chapada Diamantina, Bahia, durante período de seca prolongada, bem como, a descrição do ninho natural da espécie como o primeiro registro de ninho de M. angulosa construído em ninho abandonado da abelha Xylocopa (Neoxylocopa) cearensis Ducke (Apidae: Xylocopinae). Para o registro e descrição do ninho natural, um único ninho de M. angulosa foi estudado em um pomar de maçã (Malus domestica Borkh). Para o estudo do padrão de nidificação foi utilizada a técnica de ninhos armadilha, sendo amostrados 25 pontos ao longo do pólo agrícola, com as armadilhas postas em remanescentes de vegetação nativa. Cada ponto amostral apresentou uma distância mínima de $4 \mathrm{~km}$ do ponto mais próximo. Emergiram em laboratório um total de 19 fêmeas e 23 machos de um total de 19 ninhos fundados, com a emergência dos machos precedendo a das fêmeas. O ninho natural, ao contrário dos ninhos armadilha que foram dispostos horizontalmente, foi construído em série linear vertical sendo utilizada, como substrato, uma estaca de madeira. As nidificações se concentraram nos meses quentes, entre fevereiro e abril de 2012, porém com baixa precipitação, evidenciando influência no padrão de nidificação da espécie, indicando uma rápida resposta às alterações climáticas.

Palavras-Chave: Abelha Carpinteira; Bionomia; Ninho Natural; Xylocopini; Vespa.

Nesting Pattern of Monobia angulosa Saussure (Vespidae) During Prolonged dry Season in the Chapada Diamantina, Bahia, with Notes on Nesting in Old Carpenter-Bee Borings Xylocopa cearensis Ducke (Apidae)

Abstract. Weather can be treated as an important factor in the nesting pattern of several solitary wasps species. Nesting pattern of wasp Monobia angulosa Saussure (Vespidae: Eumeninae) was accessed in present study in the agricultural area of Mucugê-Ibicoara, Chapada Diamantina, Bahia, during an extended period of dry season. In here we also presented the first record of a natural nest in pre-existing cavities prior used by Xylocopa (Neoxylocopa) cearensis Ducke (Apidae: Xylocopinae). For a description of the M. angulosa's natural nest a single nest found in apple orchard (Malus domestica Borkh) was used. For the nesting pattern study we used the trap nests technique with 25 points along the agricultural sampled area; traps were placed in remaining native vegetation. Each sample point was at least $4 \mathrm{~km}$ apart. Emerged in the laboratory a total of 19 females and 23 males for a total of 19 established nests, males emerged prior females. Unlike the horizontal trap nests, the natural one was built in vertical linear series and a wooden stake was used as a substrate. Nesting concentrated in the warmer months, between February and April, 2012, with very low precipitation, evidencing influence on nesting pattern of this species, probably due fast response to climatic changes.

Keywords: Bionomics; Carpenter Bee; Natural Nest; Xylocopini; Wasp.

V árias são as espécies de vespas solitárias que constroem seus ninhos em cavidades pré-existentes, incluindo ninhos abandonados por outros Hymenoptera (CAMILLO et al. 1997; Grandinete \& Noll 2013). Dentre estas, podemos destacar aquelas do gênero Monobia, representado atualmente por 31 espécies distribuídas desde os Estados Unidos até o norte da Argentina, com sua maior diversidade observada na região Neotropical (HERMES \& CARPENTER 2012).

Apesar do grande número de espécies e de sua vasta área de ocorrência, poucos são os estudos detalhados sobre a bionomia do grupo. CAmillo et al. (1997), compilaram os poucos estudos relatados para o gênero, observando que apenas para Monobia quadridens (Linnaeus) existe uma maior quantidade de informações acerca da biologia de nidificação. Nesse mesmo trabalho os autores descreveram detalhadamente a biologia de
Monobia angulosa Saussure, com os ninhos monitorados em duas áreas de cerrado do estado de São Paulo nos períodos entre agosto 1986 a julho 1988 e novembro de 1990 a outubro 1992. Ainda segundo os autores, os resultados obtidos indicaram a ocorrência de duas gerações de nidificação anuais na região do experimento, ambas na estação mais quente e chuvosa.

Vários trabalhos têm demonstrado uma forte correlação entre a diversidade de vespas e a precipitação. Diniz \& KitAYAMA (1998), estudando a sazonalidade de espécies de vespas em uma área de cerrado no Brasil central, encontraram em uma mesma

Agência(s) de Financiamento: Food and Agriculture Organization of the United Nations (FAO), Global Environment Facility (GEF), United Nations Environment Programme (UNEP), Fundo Brasileiro para a Biodiversidade (FUNBIO), Fundação de Amparo à Pesquisa do Estado da Bahia (FAPESB) e ao Conselho Nacional de Desenvolvimento Científico e Tecnológico (CNPQ. 
Titofisionomia um número muito menor na abundância e riqueza de espécies na estação seca em comparação com a estação chuvosa. ElPINO-CAMPos et al. (2007), comparando os resultados obtidos em estudos realizados em áreas de cerrado nos estados brasileiros do Mato Grosso e Distrito Federal, entre os anos de 1994 e 2007, onde foi observado apenas 20-25\% de similaridade entre as espécies de vespas encontradas nessas áreas, concluíram que os resultados poderiam estar relacionados com a estação climática, entre outros fatores. Segundo esses autores, durante a estação seca e fria a disponibilidade de água representa o fator determinante na sobrevivência dos indivíduos, devido ao decréscimo nos recursos alimentares como néctar e outros insetos.

Nesse contexto, o objetivo principal do presente trabalho foi avaliar o padrão de nidificação de $M$. angulosa no pólo agrícola Mucugê-Ibicoara, Chapada Diamantina, Bahia, no ano de 2012, período marcado pela maior seca registrada para a região dos últimos 30 anos (LeIvAs et al. 2013), além de registrar e descrever, pela primeira vez, um ninho natural de $M$. angulosa construído em ninho abandonado de Xylocopa (Neoxylocopa) cearensis Ducke (Hymenoptera: Apidae: Xylocopinae).

\section{MATERIAL E MÉTODOS}

O estudo foi realizado na região de Cascavel, em uma área de cerrado localizado no pólo agrícola Mucugê-Ibicoara, na Chapada Diamantina, Bahia, Brasil, no ano de 2012. A região apresenta altitude de aproximadamente 1.100 metros e temperatura média anual de $21^{\circ} \mathrm{C}$, com médias mínima e máxima entre $16^{\circ} \mathrm{C}$ e $26^{\circ} \mathrm{C}$, respectivamente. Apresenta ainda um período chuvoso de novembro a março, com precipitação média anual de 757 $\mathrm{mm}$. A maior parte dos dados climáticos aqui apresentados foi fornecida pela estação meteorológica da empresa Bagisa S/A Agropecuária e Comércio. As médias de precipitação histórica mensais para região foram apresentadas pelo Instituto Chico Mendes (ICMBIO/MMA 2007).

Para o estudo do padrão de nidificação foram amostrados 25 pontos ao longo do pólo agrícola, com as armadilhas postas em remanescentes de vegetação nativa, como campo sujo e campo cerrado (Veloso et al. 1991). Cada ponto amostral apresentou uma distância mínima de $4 \mathrm{~km}$ do ponto mais próximo. Os espécimes de vespas foram amostrados por meio da técnica dos ninhosarmadilha [NA] (KROMBEIN 1967 modificada por TAKI et al. 2008). As inspeções em campo foram realizadas a cada 20 dias, por um período de 11 meses, totalizando 18 coletas. Os conjuntos de NA foram instalados em blocos de isopor envoltos em embalagens cartonadas usadas com as dimensões de $9 \times 9 \times 17 \mathrm{~cm}$. Esses blocos foram envolvidos em sacos de fibra têxtil vegetal, o qual além de disfarçar o aspecto da caixa, ajuda também na criação de um microclima adequado, o que pode favorecer a escolha das cavidades pelas vespas solitárias (TAKI et al. 2008). Em cada conjunto foram postos $36 \mathrm{NA}$ confeccionados em papelão, dispostos horizontalmente, sendo nove de cada diâmetro (3, 5 , 7 e $9 \mathrm{~mm}$ de diâmetro interno) e $15 \mathrm{~cm}$ de comprimento. Em cada ponto amostral foram colocados dois conjuntos de $36 \mathrm{NA}$, somando 72 NA por ponto, totalizando assim 1.800 NA. Durante as inspeções, os NA ocupados pelas vespas foram levados ao laboratório e acondicionados em estantes para aguardo da emergência dos adultos. A temperatura média do laboratório girou em torno de $24^{\circ} \mathrm{C}$, outras variáveis ambientais não foram controladas. Ao final do ano todos os ninhos foram abertos para observação da arquitetura interna, contudo como os NA foram confeccionados em papelão, muitas vezes não foi possível identificar algumas das estruturas internas do ninho em função das injúrias causadas durante a abertura dos mesmos.

Para o registro e descrição do ninho natural, um único ninho de $M$. angulosa foi estudado em um pomar de maçã (Malus domestica Borkh) pertencente à empresa Bagisa, integrante do pólo agrícola. A vespa nidificou em um ninho abandonado de
$X$. (Neoxylocopa) cearensis, que se encontrava alojado em uma estaca de madeira de sustentação da macieira, afixado próximo ao tronco da árvore que sustentava. Quando o orifício de entrada já havia sido fechado pela vespa, a estaca foi serrada e o ninho foi transportado para o Laboratório de Bionomia, Biogeografia e Sistemática de Insetos (BIOSIS/UFBA) onde foi realizado seu estudo. Para as observações do desenvolvimento dos imaturos, o fragmento da estaca contendo o ninho foi serrado em sentido longitudinal para exposição do mesmo, sendo em seguida envolto em cartolina preta e colocado em incubadora do tipo BOD, ajustada com temperatura e fotoperíodo semelhantes aos parâmetros climáticos (médias aproximadas) observados para região: entre as 6 e 18 horas - ambiente iluminado e temperatura constante igual a $26^{\circ} \mathrm{C}$; entre as 18 e 6 horas - ambiente escuro e temperatura constante igual a $18^{\circ} \mathrm{C}$. O ninho foi observado diariamente. Após a emergência os adultos foram mortos e depositados na coleção de referência do BIOSIS. Em seguida foi feito o estudo da arquitetura do ninho, onde foram mensurados o orifício de entrada, diâmetro da galeria, comprimento das células e a espessura de suas paredes.

\section{RESULTADOS E DISCUSSÃO}

$\mathrm{O}$ ano de 2012 foi considerado atípico quanto à precipitação, com apenas $420 \mathrm{~mm}$ acumulados no período (44,5\% menos que o normal). Não foi observada uma estação chuvosa bem definida e $45 \%$ do volume de chuva total registrado para o ano se concentrou em um único mês, novembro (Figura 1). De acordo com as médias entre os anos de 1964 e 2004, foi apresentada a precipitação mensal histórica do distrito de Cascavel (Figura 1).

Ninhos armadilha: $M$. angulosa nidificou em 19 NA, com a emergência de 37 indivíduos adultos. As nidificações se concentraram nos meses quentes, entre fevereiro e abril de 2012, porém com baixa precipitação (Figuras 1 e 2A). Os resultados apontam ainda a ocorrência de apenas uma geração anual. CAMILLO et al. (1997), no entanto, observaram que as nidificações no estado de São Paulo se concentraram nos meses quentes e chuvosos com a ocorrência de, pelo menos, duas gerações anuais.

Em Cascavel as vespas utilizaram os NA com diâmetros de cinco $(5,3 \%)$, sete $(10,5 \%)$ e nove $(84,2 \%)$ milímetros. Após a abertura dos ninhos foram encontrados outros 17 indivíduos mortos, totalizando 54 espécimes de $M$. angulosa identificados, destes 19 fêmeas e 23 machos. Os 12 espécimes restantes estavam danificados de forma que não foi possível a determinação do sexo. Em todos os ninhos os machos emergiram em média 72 horas antes das fêmeas, variando entre 24 e 240 horas de intervalo. Após os ninhos terem sido levados para o laboratório, as emergências ocorreram em 17 a 38 dias para os machos e 19 a 48 dias para as fêmeas. Como as inspeções em campo foram feitas em intervalos de 20 dias e não existem dados na literatura sobre o tempo necessário para a conclusão do ninho por esta espécie, não foi possível saber com precisão a duração dos estágios imaturos destes indivíduos. CAMILLO et al. (1997), no entanto, encontraram intervalos próximos para os estágios de pupa nos ninhos construídos nos meses de novembro e dezembro (12 a 17 dias para machos; 12 a 24 dias para fêmeas).

Os ninhos foram construídos em série linear, variando entre uma a seis células de cria por ninho (média de 4,5 células; Figura 2B), tendo sido construído um total de 81 células relacionando todos os ninhos estudados. O material utilizado tanto para o fechamento do ninho quanto para a separação das células foi o barro, como já observado em outros trabalhos com ninhos de $M$. angulosa (CAMillo et al. 1997) e M. quadridens (KROMBEIN 1967).

Apesar de terem sido encontrados 54 indivíduos em 81 células construídas, pôde-se observar mortes apenas nos indivíduos quase totalmente formados $(n=17)$, não tendo sido possível mensurar a mortalidade nas demais fases de desenvolvimento, 


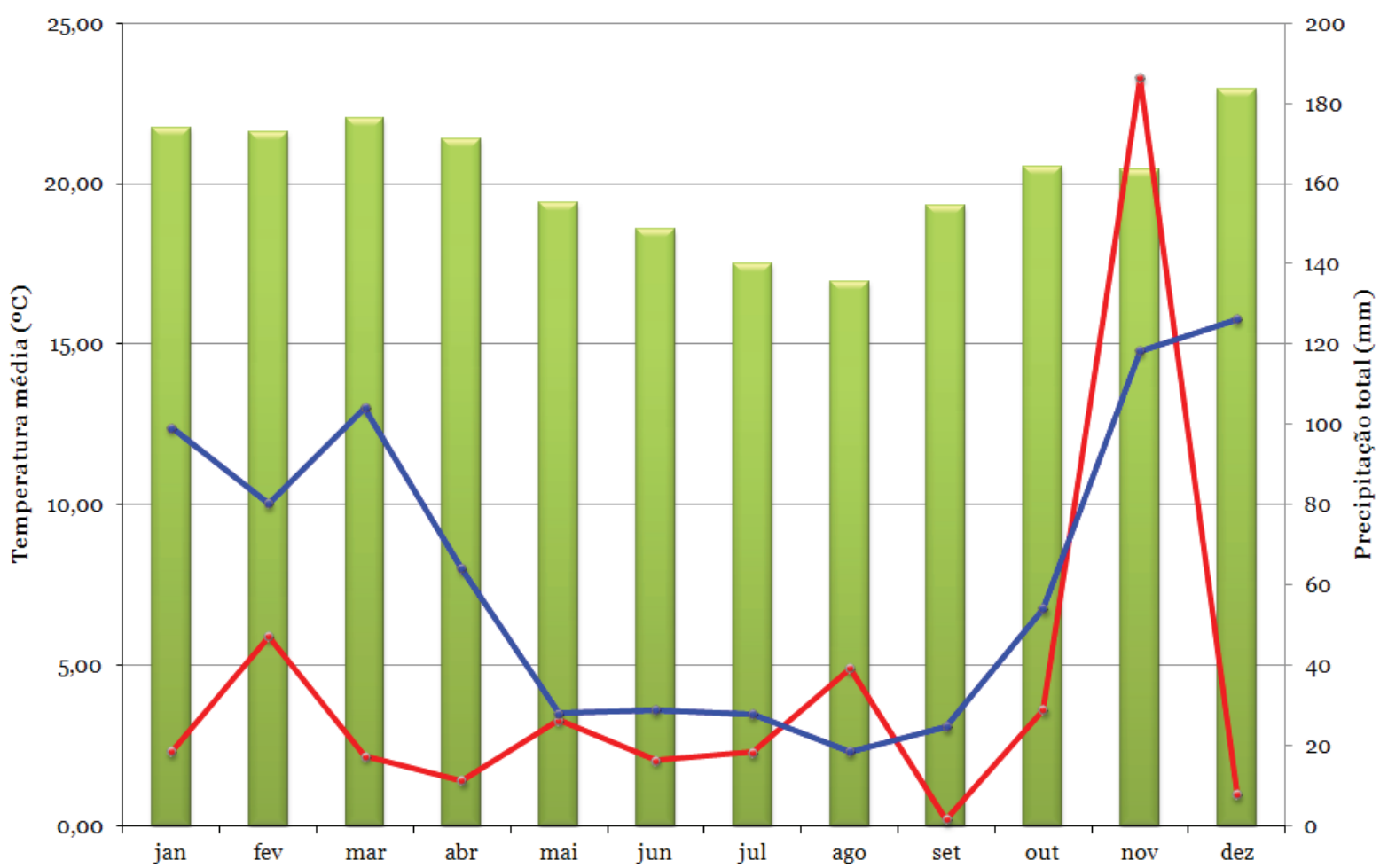

Figura 1. Temperatura média e precipitação total mensais no distrito de Cascavel, Ibicoara, Chapada Diamantina, Bahia / barras verticais (temperatura, 2012); linha vermelha (precipitação, 2012); linha azul (médias mensais da precipitação entre os anos de 1964 e 2004).
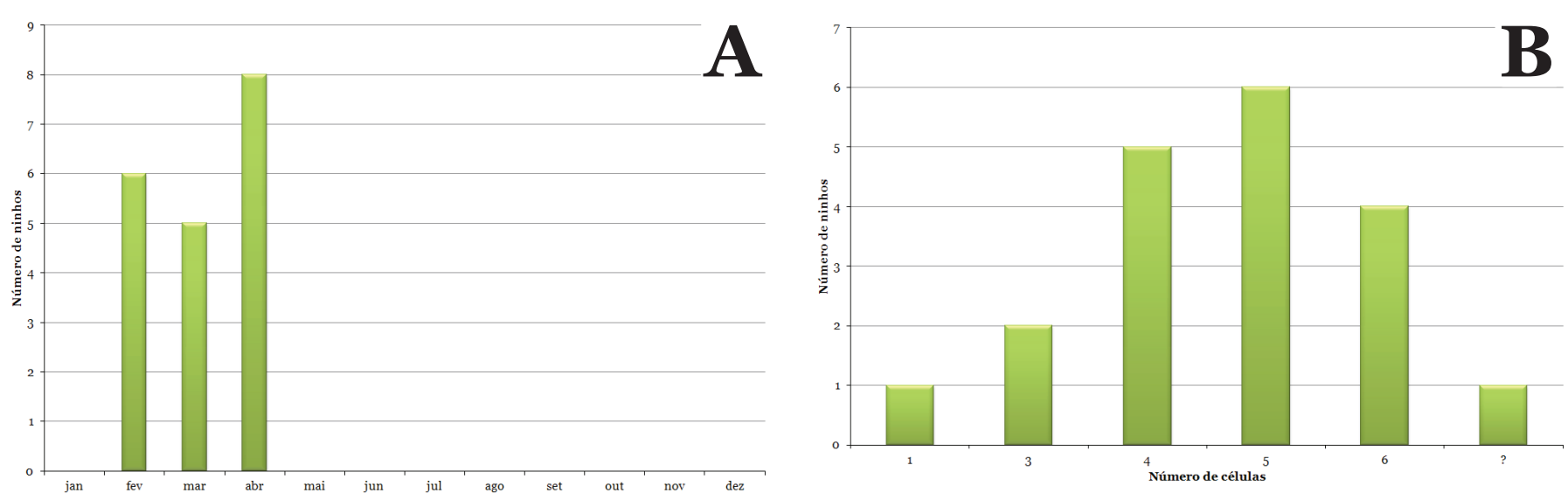

Figura 2. Dados obtidos nos ninhos de Monobia angulosa Saussure, na área de estudo durante o ano de 2012. A. número mensal de ninhos B. número total e distribuição das células por ninho.

nem mesmo visualizar possíveis células vestibulares e intercalares em função das injúrias causadas no processo de abertura dos ninhos. Também não foi possível comparar a taxa de mortalidade encontrada $(31,5 \%)$ com aquela registrada nos demais trabalhos disponíveis na literatura. Em um único ninho emergiram algumas moscas pertencentes à família Sarcophagidae que, de acordo com a literatura, já foi observada parasitando ninhos de vespas e abelhas, inclusive ninhos de M. quadridens (KROMBeIN 1967; CARvalho et al. 2012). No ninho parasitado todos os indivíduos de Monobia morreram antes de emergirem.

Ninho natural: Este é o primeiro registro de nidificação da espécie $M$. angulosa em um ninho abandonado de $X$. (Neoxylocopa) cearensis, apesar de se ter conhecimento sobre a nidificação do gênero Monobia em ninhos abandonados de abelhas-carpinteiras (KROMBEIN 1967; CAMILLO et al. 1997), mais especificamente entre as espécies $M$. quadridens e Xylocopa (Xylocopoides) virginica (Linnaeus), no sul dos Estados Unidos (ASHMEAD 1894). O ninho foi encontrado em uma estaca de suporte com 1,20 metros de comprimento, esta disposta verticalmente próxima ao tronco da macieira, favorecendo um leve sombreamento do ninho pela copa da árvore. Ao ser encontrado, no mês de junho, o ninho já havia sido fechado pela vespa. A entrada do ninho se encontrava a 0,80 metros de altura em relação ao solo. Foram mensurados os diâmetros da estaca $(41,22 \mathrm{~mm})$, do orifício de entrada do ninho (10,55 mm) e da galeria construída pela abelha $(11,82 \mathrm{~mm})$, bem como do comprimento total da galeria $(63,06 \mathrm{~mm})$, esta, ao contrário dos NA utilizados, estava disposta verticalmente.

Foram construídas três células, medindo cada uma 15,41 mm, $21,77 \mathrm{~mm}$ e $22,84 \mathrm{~mm}$, as quais preencheram por completo a galeria deixada pela abelha (Figura 3). A maior célula foi ocupada pelo macho, sendo a primeira célula contada a partir da entrada do ninho. A espessura das paredes internas de barro que separavam as três células tinha em média 1,52 $\mathrm{mm}$.

Como o ninho natural foi aberto tardiamente, apenas o estágio de pupa pôde ser acompanhado por completo. Contudo, o estágio pré-pupal observado durou entre o dia 25 de junho, quando o ninho foi aberto, até os dias sete e oito de agosto de 2012, totalizando assim 43 e 44 dias para as fêmeas e macho, respectivamente.

Dos três indivíduos do ninho natural estudado, apenas dois (1 macho e 1 fêmea) emergiram (Figura 4); o terceiro (macho) apresentou uma má formação na fase final do desenvolvimento, perecendo. A primeira fêmea iniciou a metamorfose larva-pupa 
T no dia sete de agosto de 2012 às 9h3o, a segunda às 20 ho do mesmo dia e o macho às 8 h3o do dia oito de agosto 2012. O estágio de pupa perdurou até o dia oito de setembro, totalizando assim 32 dias, quando então começaram a emergir os adultos (Figura 3B-D). Logo, entre a coleta do ninho e a emergência dos adultos se passaram aproximadamente 75 dias para ambos os sexos. CAMILLO et al. (1997) encontraram valores muito inferiores para os ninhos coletados nos meses de novembro e dezembro, no início do período chuvoso, porém em um ninho construído aproximadamente na mesma época do ano, início do período seco, os autores encontraram valores também muito altos, 152 dias (macho) e 160 dias (fêmea), indicando a ocorrência de diapausa pré-pupal para os indivíduos no início deste período. Provavelmente o ninho natural aqui observado foi fundando no início do período seco da região, em meados de março, e as condições naturais de temperatura e precipitação devem

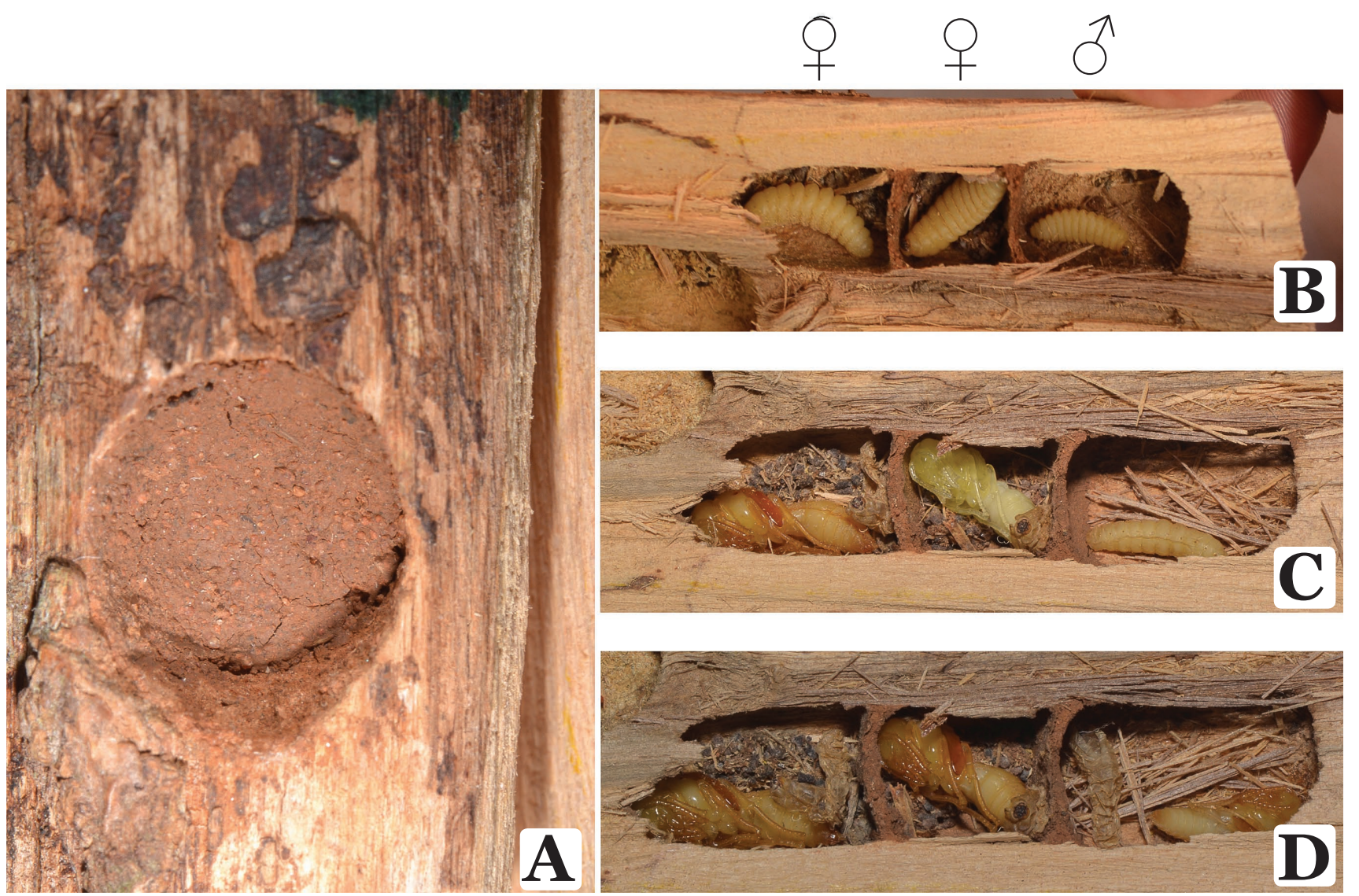

Figura 3. Ninho de Monobia angulosa Saussure proveniente da ocupação do ninho de Xylocopa (Neoxylocopa) cearensis aqui estudado. A. Orifício de entrada vedado com barro; B-D, ninho aberto mostrando o desenvolvimento dos três indivíduos. B. 25 de junho C e D. indivíduos em 07 e 08 de agosto, respectivamente. Autoria: primeiro autor.
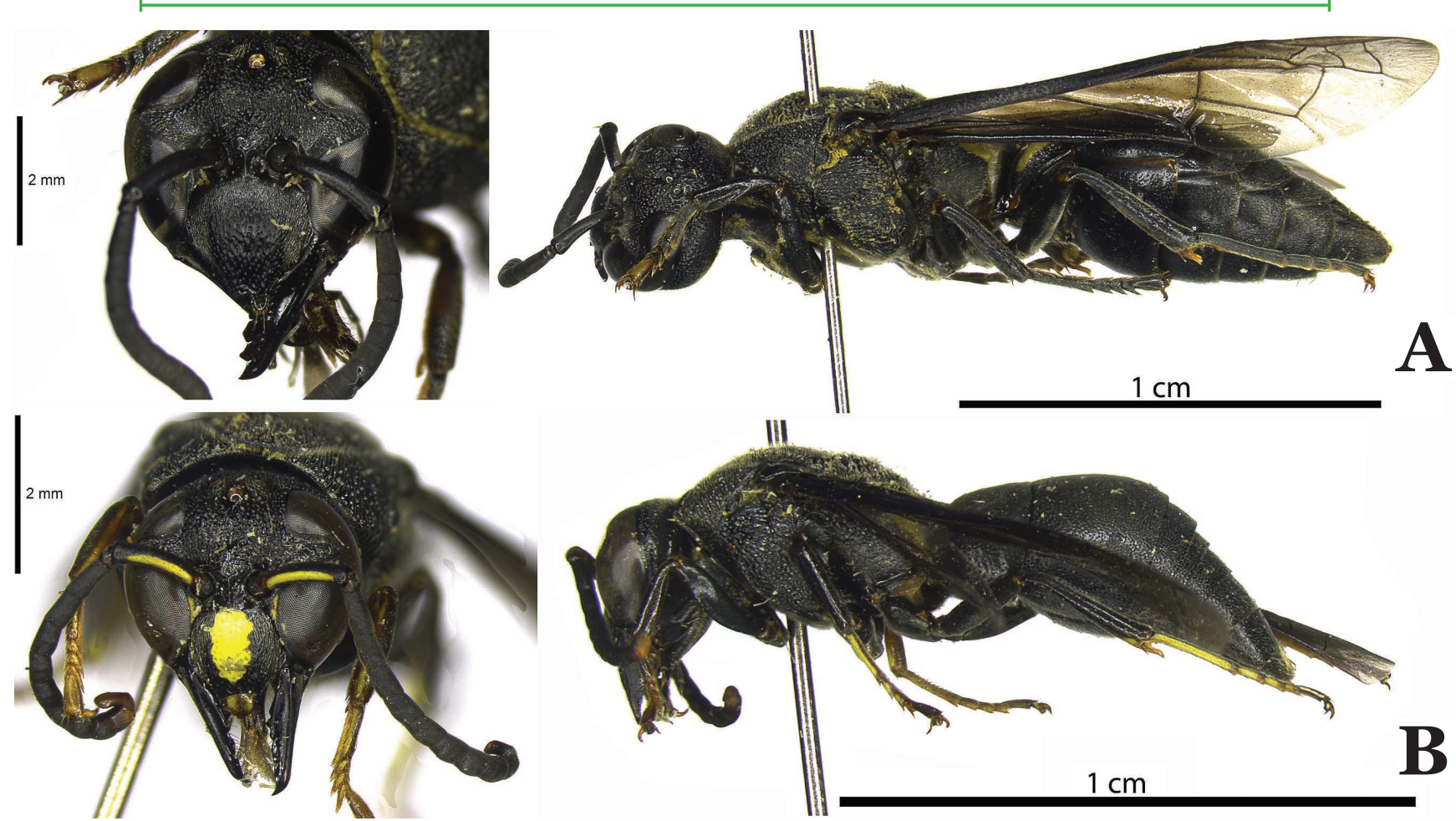

Figura 4. Espécimes de Monobia angulosa Saussure provenientes da ocupação do ninho de Xylocopa (Neoxylocopa) cearensis aqui estudado. A. Fêmea, cabeça e vista lateral, respectivamente. B. Macho, cabeça e vista lateral, respectivamente. Autoria: primeiro autor. 
ter iniciado o processo de diapausa antes de o ninho ter sido deslocado para o laboratório.

No presente trabalho foi observado um padrão de nidificação restrito ao intervalo entre dois e cinco meses após o início do período chuvoso, novembro de 2011. Contudo, a precipitação no início de 2012 ficou muito abaixo do normal para o período (Figura 1), podendo ter havido um comprometimento da segunda geração anual esperada para a espécie. Os resultados sugerem que a biologia reprodutiva da espécie pode ter sido afetada pela prolongada seca no ano de 2012, pelo menos no que diz respeito ao número de gerações daquele ano. Os resultados sobre a biologia de $M$. angulosa apontados aqui estão de acordo com aqueles já reportados na literatura, exceto o número de gerações anuais. CAmillo et al. (1997) estudando o comportamento da espécie nos períodos entre agosto 1986 a julho 1988 e novembro de 1990 a outubro 1992 em duas áreas de cerrado no estado de São Paulo, constataram haver duas gerações anuais, sendo a segunda logo após o início do período chuvoso, com o pico de nidificação ocorrendo entre dois e três meses após o início das chuvas, no mês de outubro. Os mesmos autores observaram ainda a ausência de nidificações logo após o início do período seco, ao final da primeira geração anual. A espécie $M$. angulosa apresenta rápida resposta às alterações no padrão de precipitação. Esse resultado sugere que a espécie pode ser um modelo para testar hipóteses relacionadas às alterações climáticas.

Por se tratar de um gênero de interesse agrícola, já que se alimenta basicamente de larvas de mariposas (Lepidoptera) (KROMBEIN 1967), o registro do ninho natural, bem como, a descrição das características do substrato utilizado para a nidificação por esta espécie pode ser um primeiro passo para incentivar o aumento das populações locais dessa vespa predadora nesse agroecossistema, sendo potencialmente um dos elementos favoráveis ao controle de pragas na região.

\section{AGRADECIMENTOS}

Ao Dr. Orlando Tobias Silveira (Museu Paraense Emílio Goeldi - MPEG) pela identificação das vespas aqui estudadas. Food and Agriculture Organization of the United Nations (FAO), Global Environment Facility (GEF), United Nations Environment Programme (UNEP) e ao Fundo Brasileiro para a Biodiversidade (FUNBIO), pelo suporte às coletas de campo, compra de equipamentos para os laboratórios envolvidos (através dos projetos POLINFRUT e da Rede de Taxonomia do Projeto Polinizadores do Brasil) e bolsa de pesquisa concedida ao primeiro autor (através da Rede de Taxonomia do Projeto Polinizadores do Brasil). Somos igualmente gratos à Fundação de Amparo à Pesquisa do Estado da Bahia (FAPESB) pelo suporte ao laboratório BIOSIS e à Dra. Blandina Felipe Viana, coordenadora do projeto POLINFRUT.

\section{REFERÊNCIAS}

Ashmead, W.H., 1894. The habits of the aculeate Hymenoptera. Psyche, 4: 75-79.

Camillo, E., C.A. Garófalo \& J.C. Serrano, 1997. Biologia de Monobia angulosa Saussure em ninhos armadilhas (Hymenoptera: Vespidae: Eumeninae). Anais da Sociedade Entomológica do Brasil, 26: 169-175.

Carvalho, C.J.B. de, J.A. Rafael, M.S. Couri \& V.C. Silva, 2012. Diptera, p. 701-743. In: Rafael, J.A., G.A.R. de Melo, C.J.B. de Carvalho, S.A. Casari \& R. Constantino (Orgs.). Insetos do Brasil: Diversidade e Taxonomia. $1^{\mathrm{a}}$ Ed. Ribeirão Preto: Holos Editora, v.1, 810p.

Diniz, I.R. \& K. Kitayama, 1998. Seasonality of vespid species (Hymenoptera: Vespidae) in a central Brazilian cerrado. Revista de Biologia Tropical, 46: 109-114.

Elpino-Campos, Á., K. Del-Claro \& F. Prezoto, 2007. Diversity of social wasps (Hymenoptera: Vespidae) in cerrado fragments of Uberlândia, Minas Gerais State, Brazil. Neotropical Entomology, 36: 685-692.

Grandinete, Y.C. \& F.B. Noll, 2013. Checklist of social (Polistinae) and solitary (Eumeninae) wasps from a fragment of cerrado "Campo Sujo" in the State of Mato Grosso do Sul. Sociobiology, 60: 101-106.

Hermes, M.G. \& J.M. Carpenter, 2012. Are Monobia and Montezumia monophyletic? A cladistic analysis of their species groups based on morphological data (Hymenoptera, Vespidae, Eumeninae). American Museum Novitates, 3733: $1-23$.

ICMBIO/MMA (Instituto Chico Mendes, Ministério do Meio Ambiente), 2007. Plano de manejo para o Parque Nacional da Chapada Diamantina, Versão Preliminar, Disponível em: <www.icmbio.gov.br/portal/biodiversidade/unidadesde-conservacao/biomas-brasileiros/caatinga/unidades-deconservacao-caatinga/2129-parna-da-chapada-diamantina. html >. [Acesso em 03.05.2014].

Krombein, K.V., 1967. Trap-nesting wasps and bees: life histories, nests, and associates. 1, Baltimore, Smithsonian Press, 570p.

Leivas, J.F., R.G. Andrade, L.E. Vicente, F.E. Torresan, D.d.C. Victoria \& É.L. Bolfe, 2013. Monitoramento da seca de 2011/12 a partir do NDWI e NDVI padronizado do SPOTVegetation. Anais XVI Simpósio Brasileiro de Sensoriamento Remoto - SBSR: 364-370.

Taki, H., P.G. Kevan, B.F. Viana, F.O. Silva \& M. Buck, 2008. Artificial covering on trap nests improves the colonization of trap-nesting wasps. Journal of Applied Entomology , 132: 225-229.

Veloso, H.P., A.L.R. Rangel Filho \& J.C.A. Lima, 1991. Classificação da vegetação brasileira, adaptada a um sistema universal. Rio de Janeiro: Instituto Brasileiro de Geografia e Estatística (IBGE), 124 p.

Recebido em: 02/o8/2014

Aceito em: 27/12/2014

\section{Como citar este artigo:}

Mahlmann, T., R. Lima, T. Santana, J.G. da E. Coutinho \& F.F. de Oliveira, 2015. Padrão de Nidificação de Monobia angulosa Saussure (Vespidae) Durante Estação Seca Prolongada na Região da Chapada Diamantina, Bahia, com Notas Sobre Nidificação em Ninho Abandonado de Xylocopa cearensis Ducke (Apidae). EntomoBrasilis, 8 (1): 12-16.

Acessível em: doi:10.12741/ebrasilis.v8i1.462
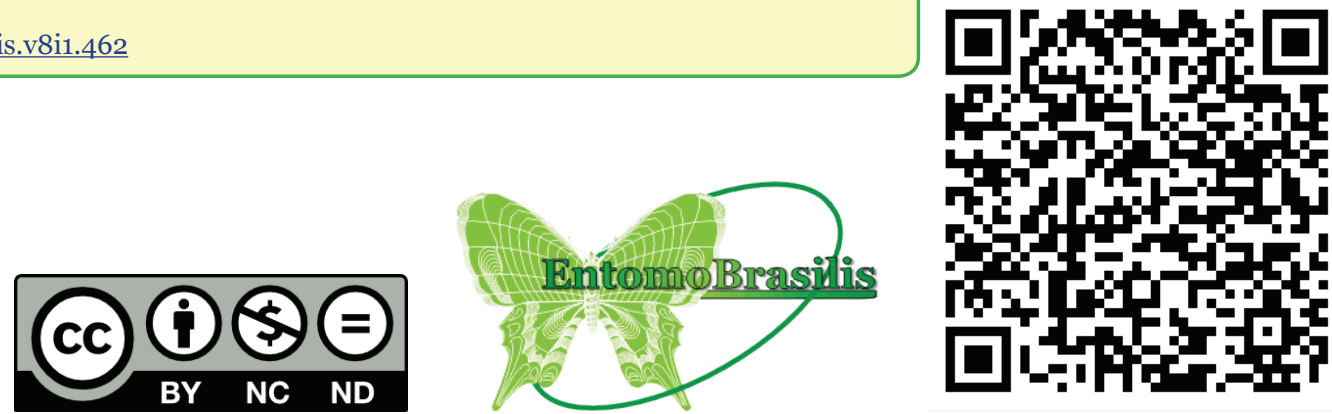